\title{
Self-sovereign Identities for Fighting the Impact of COVID-19 Pandemic
}

RACHEL BENCHAYA GANS, JOLIEN UBACHT, and MARIJN JANSSEN, Faculty of Technology, Policy and Management, Delft University of Technology, Delft, The Netherlands

Whereas part of the world can benefit from the wonders of digital technologies, undocumented migrants, asylum seekers, and refugees are facing the rough reality of being "invisible" in society and ignored by governments. During the COVID-19 pandemic, the economic impact of the closure of the service industry and the impossibility to keep most of the informal work they perform place them into a limbo without income and unemployment benefits. They are denied formal support because of the lack of a legally recognized identity. For this type of humanitarian support, contemporary identities can offer a way out. Self-sovereign identities (SSI) can provide individuals ownership over their data and the ability to share this with others. The essence is that the owner determines whom they share their identity data with. They have the sole ownership of the identity data. As such, an SSI ensures privacy for undocumented persons. This would allow to provide support to those who are left behind by a lack of formal identity. In this article, we explore the possibility of SSI to assist undocumented individuals throughout the pandemic times. SSI can be used to interact with undocumented workers and to share all kinds of identity data, such as sharing the attestation of COVID-19 tests or the ability to donate money to those who are illegal without sacrificing their identity.

CCS Concepts: • Networks $\rightarrow$ Peer-to-peer networks;

Additional Key Words and Phrases: COVID-19 pandemic, blockchain, digital identity, SSI, undocumented migrants, human rights

ACM Reference format:

Rachel Benchaya Gans, Jolien Ubacht, and Marijn Janssen. 2020. Self-sovereign Identities for Fighting the Impact of COVID-19 Pandemic. Digit. Gov.: Res. Pract. 2, 2, Article 16 (December 2020), 4 pages.

https://doi.org/10.1145/3429629

\section{COVID-19 CONSEQUENCES FOR UNDOCUMENTED WORKERS}

Undocumented workers make vital contributions to the economy and may be more affected by and vulnerable to the spread of COVID-19. In times of the pandemic, their jobs can expose them to considerable health risks. According to the Agriculture Department of the United States, more than $50 \%$ of the farmworkers are undocumented [Farmwork Justice 2018]. Despite the actual public health crises and the social isolation directive, their work was considered essential to the food supply chain. Worsening the situation, many of these migrants are exposed to the lack of appropriate personal protective equipment, threatening their health, and they cannot rely on sick payment leave or health insurance. The number of undocumented migrants living in the United States

Authors' addresses: R. Benchaya Gans, J. Ubacht, and M. Janssen, Faculty of Technology, Policy and Management, Delft University of Technology, Jaffalaan 5, Building 31, 2628 BX Delft, The Netherlands; emails: \{r.benchaya-gans, J.Ubacht, M.F.W.H.A.Janssen\}@tudelft.nl.

Permission to make digital or hard copies of all or part of this work for personal or classroom use is granted without fee provided that copies are not made or distributed for profit or commercial advantage and that copies bear this notice and the full citation on the first page. Copyrights for components of this work owned by others than ACM must be honored. Abstracting with credit is permitted. To copy otherwise, or republish, to post on servers or to redistribute to lists, requires prior specific permission and/or a fee. Request permissions from permissions@acm.org.

(c) 2020 Association for Computing Machinery.

2639-0175/2020/12-ART16 \$15.00

https://doi.org/10.1145/3429629

Digital Government: Research and Practice, Vol. 2, No. 2, Article 16. Publication date: December 2020. 
in 2017 was estimated to be $10.5 \mathrm{M}$, about $3.2 \%$ of the total population [International Organization for Migration 2020].

In Europe, the scenario is not very different. In 2018, the International Labor Organization reported that $25.1 \%$ of the economy is informal, part of which is performed by undocumented migrants [UN/ILO 2018]. A research analysis based on European data sources estimates that at least $1.9 \mathrm{M}$ undocumented migrants-and possibly as many as 3.8M-lived in Europe in 2017; the most significant numbers were in Germany, the United Kingdom, Italy, and France [Fasani 2008].

In addition to social exclusion, there is a problem of public health to be considered. The coronavirus health crisis impacted the society as a whole, but surely more drastically the ones with fewer abilities to cope with its effects. Several concerns aggravate the vulnerability of those living under undocumented status, as legally, economically, and socially their situation is not equal to the legal residents. Moreover, practical situations like the power to communicate in the local language and the cultural differences can limit access to timely and understandable information, services, resources, and safety [International Organization for Migration 2020].

According to research by the Coronavirus Resource Center of the Johns Hopkins Hospital, the number of fatal victims within the social and economic deprived communities in the United States is disproportionately high for their share of the population [Cooper 2020]. The same research points out that added to chronic medical conditions usually found in those who cannot receive medical care on a regular basis, socio-economic status inequalities, living conditions, and access to the healthcare system play an essential role in the high rates of mortality among the group to which the undocumented migrants belong [Cooper 2020].

The COVID-19 pandemic exposed the fragilities of the majority of the health systems around the globe, including the ones of privileged nations. These fragilities increased the risk of limiting access to healthcare for segments of the population and exposed one other vulnerability aspect of the undocumented migrants' lives in the health crisis context [Page et al. 2020].

Whereas legal residents criticize the use of surveillance by the government, doubting the abuse of their rights of privacy, the misuse of their data, and civil liberty violations, undocumented migrants' distress goes beyond these concerns. Living under unstable situations and with the constrictions of anti-immigration laws in many countries, the fear of detention and deportation is added to their concerns. Therefore, it is very unlikely that this group will voluntarily adhere to technology projects in which their privacy is put at risk. Considering that the number of undocumented migrants is significantly high in several countries, the adoption of a contact tracing mobile app is probably destined to fail in many communities. This situation raises the risks of another emergency in public healthcare.

\section{BLOCKCHAIN-BASED SELF-SOVEREIGN IDENTITY}

Having an identity can support undocumented migrants in having access to healthcare and other means of support during the pandemic. It can also support government measures in their battle to contain the virus, e.g., by means of tracking and tracing. Blockchain-based applications can be used to provide undocumented migrants with an identity that will not endanger their privacy or lead to detention or deportation.

Blockchain projects related to Self-Sovereign Identity (SSI) can have a high-scale impact on government operations [Janssen et al. 2020; Ølnes et al. 2017]. An SSI must allow users to make claims, and others should be able to verify that these claims are correct. There is no consensus about what constitutes an SSI; however, there are some essential characteristics:

- The user is in control of sharing data.

- Privacy is ensured.

- Data can only be shared based on consent by its bearer.

- Others should not be able to mutate data.

- Others are able to rely on the correctness of the data.

Digital Government: Research and Practice, Vol. 2, No. 2, Article 16. Publication date: December 2020. 


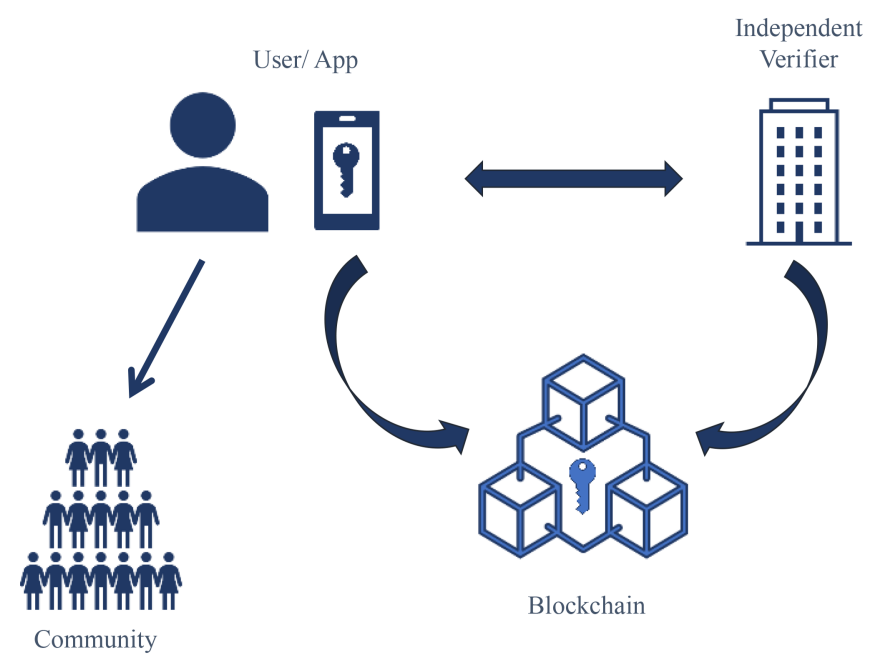

Fig. 1. Overview of a blockchain-based SSI (own illustration).

SSIs are often blockchain-based to store and share data associated with a person's identity. Blockchain ensures that the data are not easy to mutate without knowing, ensures transparency and privacy, and that data can be shared on the basis of consent by the bearer. With SSI, the person can use an app to verify who they are and allows the ability to share specific identity data with others. For example, attestations, like the outcomes of a COVID-19 test, can be stored and trusted because of the near immutability of the blockchain technology. An independent verifier guarantees the correctness of the SSI (illustrated in Figure 1).

Through an SSI, individuals are able to exercise their most fundamental right: to be recognized as a person and become "visible." This argument becomes more relevant in times of crisis like the one in due course. The structure provided by blockchain technology on projects of SSI is based on the individual as a sovereign actor, decentralizing the system from the State. Among the impacts these projects may lead to, include access to services provided by NGOs and a wide range of rights to underserved individuals.

Furthermore, blockchain proves to be an alternative to patient data management in a secure and efficient way, safeguarding healthcare records, personal information, and essential medical history information [Attaran \& Gunasekaran 2019]. On a similar approach to SSI projects, blockchain for healthcare bases its premises in a patient-centric system that, by definition, already promises a potential impact by improving the security of medical information.

As blockchain technology reduces the requirement of government authorities' intermediaries, precluding effective State control and shifting the power to a decentralized blockchain-based network, the fear of undocumented migrants in making use of an SSI may be mitigated. Another positive point for the adoption of blockchainbased SSI is the privacy aspect. Due to its decentralized network of peers, personal and sensitive data are less susceptible to attacks and misuse, giving the power to the users to manage and control their data without compromising security but keeping the ability of autonomously choosing third parties to provide personalized services [Zyskind et al. 2015].

Considering the attributes of blockchain-based applications, the development of a temporary SSI with the possibility to carry medical information could have an outstanding impact on the lives of undocumented migrants, but also all people in society. The adoption could potentially promote inclusiveness to this group and benefit the host community as a whole by slowing down the virus spread. The possibility to add information about medical background would create the potential for these individuals to reach medical assistance. They can use 
an SSI for their attestations that they have been tested for COVID-19. This possibility might help to control the contamination and avoid massive spreads within the undocumented community and the society at large.

Similarly, as undocumented workers are ineligible for emergency government benefits or State unemployment support without a valid work permit, donations-from money to personal protective equipment-could be easily traced. By ascertaining that the most in need are the final recipients of donations, perhaps the society would feel more encouraged to provide additional support to this community.

Ideally speaking, the use of SSI providing accessibility to basic rights to undocumented individuals should become the standard in normal times and even stronger in the response of crises. It is essential to build confidence among the undocumented migrants from the very beginning of the development of these technologies to foster that users would trust technologies that they are familiar with, as recommended by the International Organization for Migration [2020]. Principles of data protection and ethical considerations are foremost to build trust in the adoption of any technology within a community that historically is excluded, ignored by the system, and lives under the fear of deportation.

\section{FURTHER RESEARCH}

SSI provides many opportunities for fighting COVID-19. The ability to share attestations and medical information controlled by the individual are among the well-known examples. Also, SSI can provide an identity to undocumented workers to give them access to aid and medical services. Although undocumented workers have been crucial for the economy, they have been neglected during the pandemic. There is no consensus about what constitutes an SSI and what an SSI should look like for certain situations. For digital governments, SSI will play a key role, and ample research is needed to take full benefit of the possibilities that blockchain-based SSI can offer. This requires further research into the alignment of the technical, institutional, and societal aspects of SSI. The COVID-19 pandemic illustrates the urgency for the development of blockchain-based SSI for digital governments worldwide.

\section{REFERENCES}

M. Attaran and A. Gunasekaran. 2019. Healthcare and life sciences. In Applications of Blockchain Technology in Business. Springer Briefs in Operations Management.

L. A. Cooper. 2020. Coronavirus research center of Johns Hopkins University. Retrieved from https://coronavirus.jhu.edu/data/racial-datatransparency.

Farmworker Justice 2018. Selected statistics on farmworkers. Washington, USA. Retrieved from https://www.farmworkerjustice.org/sites/ default/files/resources/NAWS\%20data\%20factsht\%2010-18-18.pdf.

F. Fasani. 2008. Undocumented migration counting the uncountable. Data and Trends across Europe. CLANDESTINO Project. EU, Brussels.

International Organization for Migration. 2020. World Immigration Report 2020. Retrieved from https://publications.iom.int/system/files/ pdf/wmr_2020.pdf.

M. Janssen, V. Weerakkody, E. Ismagilova, U. Sivarajah, and Z. Irani. 2020. A framework for analyzing blockchain technology adoption: Integrating institutional, market and technical factors. Int. f. Inf. Manag. 50 (2020), 302-309. DOI : https://doi.org/10.1016/j.ijinfomgt.2019. 08.012

S. Ølnes, J. Ubacht, and M. Janssen. 2017. Blockchain in government: Benefits and implications of distributed ledger technology for information sharing. Gov. Inf. Quart. 34, 3 (2017), 355-364. DOI : https://doi.org/10.1016/j.giq.2017.09.007

K. R. Page, C. Beyrer, and S. Polk. 2020. Undocumented U.S. Immigrants and Covid-19. New England F. Med. 382 (2020), e62. DOI: 10.1056/ NEJMp2005953

G. Zyskind, O. Nathan, and A. Pentland. 2015. Decentralizing privacy: Using blockchain to protect personal data. In Proceedings of the IEEE Security and Privacy Workshop. 180-184. DOI : 10.1109/SPW.2015.27

Received July 2020; revised September 2020; accepted October 2020

Digital Government: Research and Practice, Vol. 2, No. 2, Article 16. Publication date: December 2020. 